\title{
Minimally invasive plate osteosynthesis with a locking compression plate is superior to open reduction and internal fixation in the management of the proximal humerus fractures
}

\author{
Tao Lin ${ }^{\dagger}$, Baojun Xiao ${ }^{\dagger}$, Xiucai Ma, Dehao Fu and Shuhua Yang
}

\begin{abstract}
Background: The use of minimally invasive plate osteosynthesis (MIPO) via anterolateral deltoid splitting has good outcomes in the management of proximal humerus fractures. While using this approach has several advantages, including minimal soft tissue disruption, preservation of natural biology and minimal blood loss, there is an increased risk for axillary nerve damage. This study compared the advantages and clinical and radiological outcomes of MIPO or open reduction and internal fixation (ORIF) in patients with proximal humerus fractures.

Methods: A matched-pair analysis was performed, and patient groups were matched according to age ( \pm 3 years), sex and fracture type. Forty-three pairs of patients (average age: MIPO, 63 and ORIF, 61) with a minimum follow-up of 12 months were enrolled in the study group. The patients were investigated radiographically and clinically using the Constant score.

Results: The MIPO technique required less surgery time and caused less blood loss compared to ORIF ( $p<0.01)$. In addition, MIPO required a smaller incision, resulted in less scarring, and was cosmetically more appealing and acceptable to female patients than ORIF. Following MIPO, patients had better functional results at 3 and 6 months, with better outcomes, less pain, higher satisfaction in activities of daily living, and a higher range of motion when compared to ORIF $(p<0.05)$. Fracture configuration, according to the AO/ASIF(Association for the Study of Internal Fixation) fracture classification, did not significantly influence the functional results. The complication rate was comparable between both groups.
\end{abstract}

Conclusion: The use of MIPO with a locking compression plate in the management of proximal humerus fractures is a safe and superior option compared to ORIF.

Keywords: Proximal humeral fractures, Minimally invasive, MIPO, Locking compression plate

\section{Background}

There are a variety of surgical options for the treatment proximal humerus fractures, including open reduction internal fixation (ORIF), intramedullary device fixation, external fixation and hemi arthroplasty. Of these, ORIF is the most commonly used technique for the majority of fractures [1-5]. However, there is much debate on

\footnotetext{
* Correspondence: fudehao@qq.com

${ }^{\dagger}$ Equal contributors

Department of Orthopedics, Union Hospital of Tongji Medical College,

Huazhong University of Science and Technology, Wuhan 430022, Hubei Province, China
}

(c) 2014 Lin et al.; licensee BioMed Central Ltd. This is an Open Access article distributed under the terms of the Creative

what method or technique for ORIF is optimal, and the decision is often based on the fracture configuration and surgical experience [6-12]. Recent literature has indicated that intramedullary nailing is most suitable for managing two-part proximal humerus fractures. Most surgeons agree that ORIF with a plate is the ideal technique for managing comminuted and 3 or 4 part fractures [13]. This particular technique can also be performed with minimally invasive techniques, which is known as minimally invasive plate osteosynthesis (MIPO). 
Previous studies have shown that the traditional deltopectoral approach to the proximal humerus provides limited access to the posterolateral aspect of the shoulder and that the visualization and reduction of a large retracted greater tuberosity fragment may be difficult [11,14-18]. The deltopectoral approach requires extensive soft tissue dissection and muscle retraction to gain adequate exposure to the lateral aspect of the humerus $[10,11,14,16,18-20]$. This can cause further devascularization of fracture fragments during dissection and plating, leading to the disruption of critical blood supplies to the humeral head [10,18-20]. The deltoid splitting approach, which is an alternative method, provides good visualization of the posterolateral aspect of the shoulder without extensive soft tissue dissection or forcible retraction; however, there is an increased risk of injuring the axillar nerve as compared to the conventional deltopectoral approach [16,21,22]. Recently, many studies have demonstrated the superiority of MIPO techniques via anterolateral deltoid splitting combined with skin incisions for the management of proximal humerus fractures $[15,17,19,21-28]$. This method is a minimally invasive technique, leading to less soft tissue injury, decreased postoperative pain, and decreased functional loss. In addition, MIPO allows for the visualization of the axillary nerve $[12,14,16,22]$. Thus, MIPO is a safe and effective method for the treatment of proximal humerus fractures $[14,19,20,22]$.

Despite these results, a consensus amongst orthopedic surgeons on the best treatment for proximal humerus fractures has not been determined [7,28]. Although many of the complications associated with MIPO are related to incorrect surgical technique, many surgeons still prefer to use the conventional ORIF with the deltopectoral approach [29]. The objective of this study was to compare MIPO using a locking compression plate and ORIF using a deltopectoral approach in the management of proximal humerus fractures. We compared surgical advantages of each technique, radiograph outcomes, the incidence of nerve injury, and functional deficits during a one year follow-up period.

\section{Methods}

\section{Patient information}

This was a retrospective case control study including two groups. Between September 2007 and April 2012, 184 patients with displaced proximal humerus fractures were treated with LCP (Locking Compression Plate) according to Neer criteria in Union hospital, Tongji Medical College, Huazhong University of Science and Technologe. Of these, 118 were treated with ORIF via a traditional deltopectoral approach between September 2007 and June 2010, while 66 were treated with MIPO via anterolateral deltoid splitting between June 2010 and
April 2012. Patients with pathological fractures, head split fractures, open fractures, fractures with primary neurovascular damage and cases lost to follow-up were excluded from the study. After these exclusions, 158 patients remained in the study. Of these 158 patients, 86 (43 pairs) were selected for a retrospective matchedpaired analysis according to age ( \pm 3 years), gender, and fracture type with a minimum follow-up of 12 months (range, 12-17months). Thus, inclusion bias could be excluded.

The median age of the MIPO group was 63 years compared to 61 years in the ORIF group. The distribution of age and sex by group was 27 (62\%) women and 16 (38\%) men in the MIPO group, and 31 (72\%) women and $12(28 \%)$ men in the ORIF group. According to the AO/ASIF classification system, the most frequent type of fracture was type B $(n=46 ; 53.5 \%)$, with 19 (22.1\%) type A and 21 (24.4\%) type $\mathrm{C}$ fractures. There were 10 type $A, 24$ type $B$ and 9 type $C$ fractures in the MIPO group, and there were 9 type A, 22 type B and 12 type $C$ fractures in the ORIF group (Table 1 ).

\section{Implant}

The LCP plate (titanium; thickness: $4.2 \mathrm{~mm}$; width: $12 \mathrm{~mm}$; length: 105-231 mm; Double Engine Medical Material Company, China) was anatomically pre-contoured with threeto ten holes on the plate shaft and nine holes for head screws. The proximal suture holes were applied to secure the tuberosity fragments and the plate.

\section{Surgical technique}

In both the MIPO and ORIF groups, the patients were positioned in the beach-chair or supine position to allow two plane intraoperative $\mathrm{C}$-arm image intensifier views $[8,11,12,16,18,19,30-32]$. All of the procedures were performed under general anesthesia with administration of a broad-spectrum antibiotic prophylaxis $[16,18,22,30]$. In the ORIF group, ORIF was performed using a standard deltopectoral approach with a LCP. The $12-14 \mathrm{~cm}$ incision started at the tip of the coracoid process and ran laterally

Table 1 Patient demographics

\begin{tabular}{llll}
\hline Characteristic & \multicolumn{2}{l}{ Treatment } & $\begin{array}{l}\mathbf{P} \\
\text { value }\end{array}$ \\
\cline { 2 - 3 } & MIPO $(\mathbf{n}=\mathbf{4 3})$ & ORIF $(\mathbf{n}=\mathbf{4 3})$ & 0.357 \\
\hline Gender & $27(62 \%)$ & $31(72 \%)$ & \\
Memale & $16(38 \%)$ & $12(28 \%)$ & \\
Age, years & $63 \pm 14$ & $61 \pm 12$ & 0.414 \\
AO classification & & & 0.753 \\
type A & $10(23.2 \%)$ & $9(20.9 \%)$ & \\
type B & $24(55.8 \%)$ & $22(51.2 \%)$ & \\
type C & $9(20.9 \%)$ & $12(27.9 \%)$ & \\
\hline
\end{tabular}


in the direction of the insertion of the deltoid muscle (Figure 1F). Reduction was enabled with a K-wire under fluoroscopy according to the landmarks of the long head of biceps, the greater and lesser tubercles, and the intertubercular groove $[26,30]$. After the fracture was anatomically reduced, a LCP was placed $1 \mathrm{~cm}$ posterior to the intertubercular groove $[11,30]$ and $1 \mathrm{~cm}$ distal to the tip of the greater tubercle $[15,27]$.

In the MIPO group, the anterolateral deltoid splitting approach was utilized, and the tip of the acromion was palpated and used as a landmark [14,19]. A line perpendicular to the palpable shaft of the humerus was drawn $5 \mathrm{~cm}$ distal to the tip of the acromion. A second parallel line was drawn $2 \mathrm{~cm}$ further distal to the first line (Figure 1B). The area between these two lines contained the axillary nerve and was considered the unsafe zone. A longitudinal incision was made on the lateral side of the humerus starting from the lateral acromial border and ending distally $5 \mathrm{~cm}$ was to access the proximal humerus, the greater tuberosity and the humeral head (Figure 1E). To insert distal screws, a distal incision was made $7 \mathrm{~cm}$ distal to the acromion and was approximately 2.5-3.5 cm long (Figure 1E). In most cases, good reduction was achieved by applying

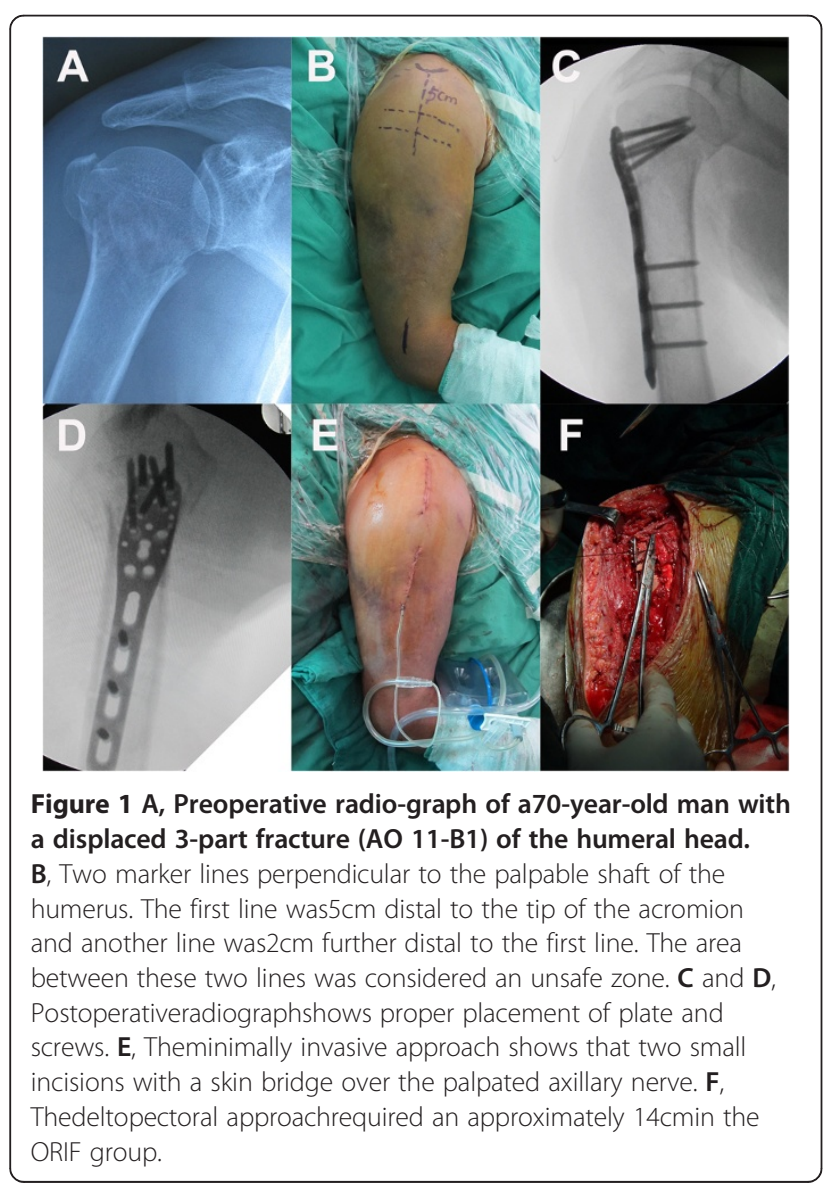

axial traction on the humerus and pulling the rotator cuff $[6,8,22,23,33]$. In some cases, indirect reduction techniques, such as ligamentotaxis, were used. Plate reduction was performed in cases of a valgus displaced fracture configuration [22,28]. The LCP was placed proximally below the apex of the greater tuberosity to maintain reduction. If non-absorbable sutures were used, they were secured to the suture wires holes in the LCP $[6,11,16,19,21-23,26,28,33]$. The plate was anchored proximally with multiple angled stable screws into the humeral head fragment. After removing the aiming arm, the non-absorbable sutures were tightened to the LCP [21-23].

Patients in both groups had individual patient-related postoperative management. In the majority of cases, the patients' arm was placed in a sling for a maximum of two weeks. Passive and active range of motion exercises were started after surgery, depending on pain and activity level $[6,11]$.

\section{Ethics and consent}

This study has been performed in compliance with the Helsinki Declaration and has been granted an exemption from Hospital's Ethics Committee of Union Hospital of Tongji Medical College. The patients were informed and have written informed consent; all patients were over 18 years old. The classic cases in this article have been undertaken with the patient's consent.

\section{Data analysis}

We used SPSS 18 statistical software for Windows for all analyses. For normally distributed data (patient age, time between fracture and fixation, operative time, blood loss, hospital stay, and follow-up time), an independent sample t-test was used. For data that was not normally distributed data (AO classification and the Constant shoulder score), the Mann-Whitney rank sum test was used. For categorical data (gender and fracture pattern), a chi-square test was used. A P-value $<0.05$ was considered statistically significant.

\section{Results}

\section{Follow up}

We performed clinical and radiographic assessments 3, 6 and 12 months after surgery [6,11]. At each follow-up, the Constant score was used to assess shoulder function. Standardized X-rays were obtained in anteroposterior and transscapular views to evaluate fracture healing, avascular necrosis, placement of the plate, and quality of reduction. Complications were evaluated based on follow-up radiographs and a retrospective chart review of the patients' medical records to determine the incidence of humeral head necrosis, delayed union, implant failure or a neurological deficit. 
Table 2 Surgical and follow-up data

\begin{tabular}{llll}
\hline Characteristic & \multicolumn{2}{l}{ Treatment } & \\
\cline { 2 - 3 } & $\begin{array}{l}\text { MIPO } \\
(\mathbf{n = 4 3 )}\end{array}$ & $\begin{array}{l}\text { ORIF } \\
(\mathbf{n = 4 3 )}\end{array}$ & P value \\
\hline Average length of surgery in min & $71 \pm 8.7$ & $79 \pm 11.7$ & 0.0007 \\
Average length of hospital stay in days & $\mathbf{6 . 8} \pm 1.8$ & $\mathbf{7 . 7} \pm 1.5$ & 0.046 \\
Average blood loss (ml) & $126 \pm 54.8$ & $213 \pm 68.4$ & 0 \\
Average duration between trauma & $\mathbf{5 . 0} \pm 1.9$ & $\mathbf{6 . 3} \pm 1.8$ & 0.0012 \\
$\begin{array}{l}\text { and surgery(day) } \\
\text { Follow-up(months) }\end{array}$ & $12.6 \pm 1.4$ & $13.1 \pm 0.9$ & 0.067 \\
The rate of union (at 6 months) & $\mathbf{9 3 \%}$ & $97.7 \%$ & \\
\hline
\end{tabular}

To perform the retrospective matched-paired analysis, we selected patients according to age ( \pm 3 years), gender and fracture types. The patient demographics of 86 patients are listed in Table 1 . The analysis revealed no significant differences in group demographics, including $\mathrm{AO} / \mathrm{ASIF}$ classification and mean age $(\mathrm{p}>0.05)$. However, there was a higher female ratio in the ORIF group compared to the MIPO group $(p>0.05)$. The average duration between trauma and surgery in the MIPO group was 5 days and 6.3 days in the ORIF group. In addition, MIPO required less surgery time and resulted in less blood loss (both $\mathrm{p}<0.01$ ). The union rate at 6 months was $93 \%$ in the MIPO group and $97.7 \%$ in the ORIF group (Table 2).

The Constant score was higher in the MIPO group at the 3 and 6 month follow-up time points compared to the ORIF group $(\mathrm{P}=0.033$ and $\mathrm{P}=0.043$ ) (Figure 2 ). At the 12 month follow-up, the Constant score was not statistically significant $(\mathrm{P}=0.065)$ (Figure 2 ). In addition, patients in the MIPO group experienced significantly less pain, higher satisfaction in activities of daily living, and greater range of motion at the 3 and 6 months follow-up time points $(\mathrm{p}<0.05)$. The level of strength was not significantly different at these time points $(p>0.05)$.
At the 12 month follow-up, there were no significant differences in both groups (Table 3 ).

At the 12 month follow-up, type A fractures had the highest average Constant score in both groups (MIPO: $76.2 \pm 7.1$, ORIF: $75.6 \pm 10.8$ ), followed by type B fractures (MIPO: $71.7 \pm 11.3$, ORIF $69.0 \pm 14.2$; ORIF: $69 . \pm 13.9$ ) and type C fractures (MIPO: 69.4 \pm 17.1 , ORIF: $69.8 \pm 13.2$ ) (Figure 3$)$. The type of fracture between groups was not significantly different $(\mathrm{p}=0.205)$.

In the MIPO group, 5/43 patients experienced complications and $4 / 43$ patients experienced complications in the ORIF group (Table 4). No patients developed wound infection and nonunion after one year of follow-up in both groups. In 3 patients (group MIPO, 2 patients, type $\mathrm{B}$ and $\mathrm{C}$; group ORIF, 1 patient, type $\mathrm{B}$ ), the fracture collapsed after 3 months, leading to a varus malalignment. These patients developed loss of reduction and underwent reoperation either by reosteosynthesis combined with cancellous grafting or by joint replacement. One patient in the MIPO group presented with clinical signs of axillary injury, which was characterized by poorly localized posterior shoulder pain, parenthesis over the lateral aspect of the shoulder, and deltoid muscle weakness. Axillary nerve injury was confirmed on electromyography examination. However, there was no functional impairment when the patient was assessed at one year follow-up. One plate in the MIPO group and two plates in the ORIF group were removed due to subacromial impingement after radiographs confirmed fracture union at about 5 months. In the ORIF group, one patient underwent reoperation to change a perforated screw 3 months after the initial operation.

\section{Discussion}

The objective of this study was to compare MIPO and ORIF with a LCP plate to treat proximal humerus fracture. Our retrospective comparative study showed

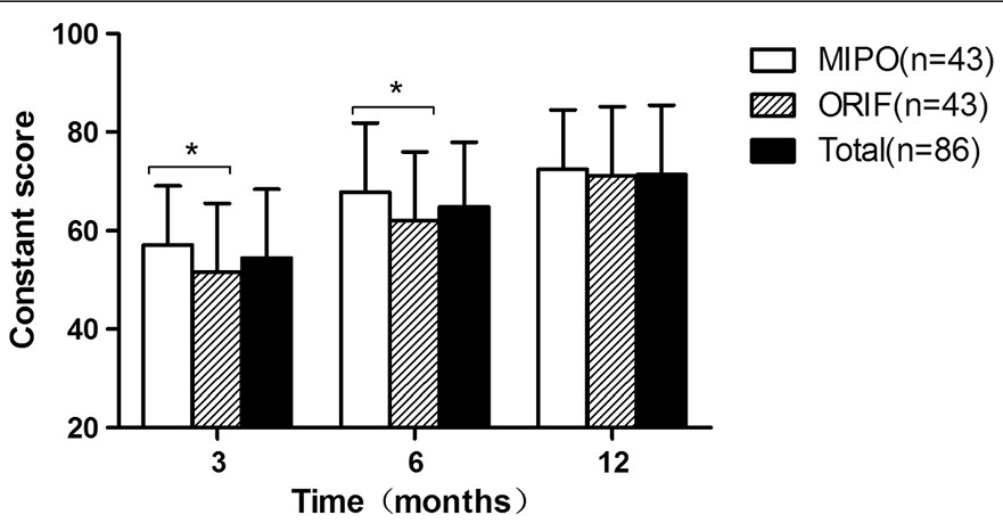

Figure 2 Mean value of Constant score at each follow up. Mean values of the Constant score for all patients (total), MIPO and ORIF at 3, 6 , and 12 months (* $\mathrm{p}<0.05$ ). 
Table 3 Subjective parameters of the constant score

\begin{tabular}{|c|c|c|c|c|c|c|c|c|c|}
\hline \multirow[t]{2}{*}{ Score } & \multicolumn{3}{|c|}{3 months } & \multicolumn{3}{|c|}{6 months } & \multicolumn{3}{|c|}{12 months } \\
\hline & MIPO $(n=43)$ & ORIF $(n=43)$ & $P$ value & MIPO $(n=43)$ & ORIF $(n=43)$ & $P$ value & MIPO $(n=43)$ & ORIF $(n=43)$ & $P$ value \\
\hline Pain & $8.8 \pm 3.4$ & $7.2 \pm 2.9$ & 0.020 & $12.8 \pm 3.1$ & $11.3 \pm 3.3$ & 0.007 & $13.3 \pm 2.8$ & $12.8 \pm 3.2$ & 0.373 \\
\hline $\mathrm{ADL}$ & $14.5 \pm 3.0$ & $12.8 \pm 2.8$ & 0.012 & $15.6 \pm 3.3$ & $14.0 \pm 2.7$ & 0.039 & $17.1 \pm 3.1$ & $16.0 \pm 2.9$ & 0.073 \\
\hline $\mathrm{ROM}$ & $25.6 \pm 3.9$ & $23.6 \pm 4.0$ & 0.022 & $29.7 \pm 4.1$ & $26.9 \pm 4.1$ & 0.002 & $30.3 \pm 3.6$ & $29.7 \pm 4.1$ & 0.438 \\
\hline Strength & $8.23 \pm 2.3$ & $7.9 \pm 2.2$ & 0.536 & $9.7 \pm 3.1$ & $10.2 \pm 2.9$ & 0.195 & $11.5 \pm 3.2$ & $12.3 \pm 3.4$ & 0.287 \\
\hline Total & $57.1 \pm 12$ & $51.6 \pm 14$ & 0.033 & $67.7 \pm 14$ & $62.0 \pm 14$ & 0.040 & $72.5 \pm 12$ & $71.2 \pm 14$ & 0.652 \\
\hline
\end{tabular}

$A D L$ activities of daily living; $R O M$ range of motion.

that the MIPO technique was superior to ORIF in the management of proximal humerus fractures. First, the MIPO group required less surgery time, resulted in less blood loss, and the patients required a relatively shorter hospital stay. Second, the MIPO group had better shoulder function at 3 and 6 months, with less pain, higher satisfaction in activities of daily living and greater range of motion $(\mathrm{p}<0.05)$. The complication rate was comparable between both groups (MIPO:11.6\%;ORIF:9.3\%).

The MIPO technique provides good visualization of the posterolateral aspect of the shoulder via a small incision without extensive soft-tissue dissection or forcible retraction. Thus, it is relatively easy to perform a reduction of a large greater tuberosity fragment under direct vision and significantly reduces the intra-operative time. These findings were in accordance to previous reports $[11,19,23,28]$.

In this study, Constant scores based on fracture type were similarly distributed in both groups. In general, type A fractures had the highest average Constant score, followed by type $B$ and $C$ fractures. However, when subgroup analysis was carried out, the Constant scores were higher for type A and B fractures treated with MIPO. This was in contrast with previous reports by Hepp et al. [11].

In this study, the technique (MIPO/ORIF) employed had no significant influence on the final functional muscle weakness and shoulder range of motion. In addition, these findings were independent of an axillary nerve injury. These findings are not consistent with the findings from Hepp et al. [11]. Their study suggested that the ORIF technique had a higher deltoid muscle level at 3 and 6 months follow up. In addition, there was less soft tissue disruption in the MIPO group, most likely leading to a greater range of movement when compared to the ORIF group. Taken together, these findings indicate that the MIPO technique is safe and has a low risk of axillary nerve injury for treating proximal humerus fractures.

Previous anatomical studies have revealed that axillary nerve lesions occur between $5.58 \mathrm{~cm}$ to $6.66 \mathrm{~cm}$ distal to the lateral acromion $[14,34,35]$. In this study, to prevent the axillary nerve damage, we split the deltoid no more than $5 \mathrm{~cm}$ distal to the mid-acromion in any given vertically neutral position [16,35]. For the second incision to place distal screws, we recommend a starting deltoid split point at least $7 \mathrm{~cm}$ distal to the acromion, while Cheung [35] suggests $9 \mathrm{~cm}$. In our study, none of the patients required an extension of the incision. Axillary nerve palsy in one patient was most likely due to sliding of the LCP plate. A study by Visser et al. [36,37] showed that axillary nerve lesions were more frequent in proximal humeral fractures, with an

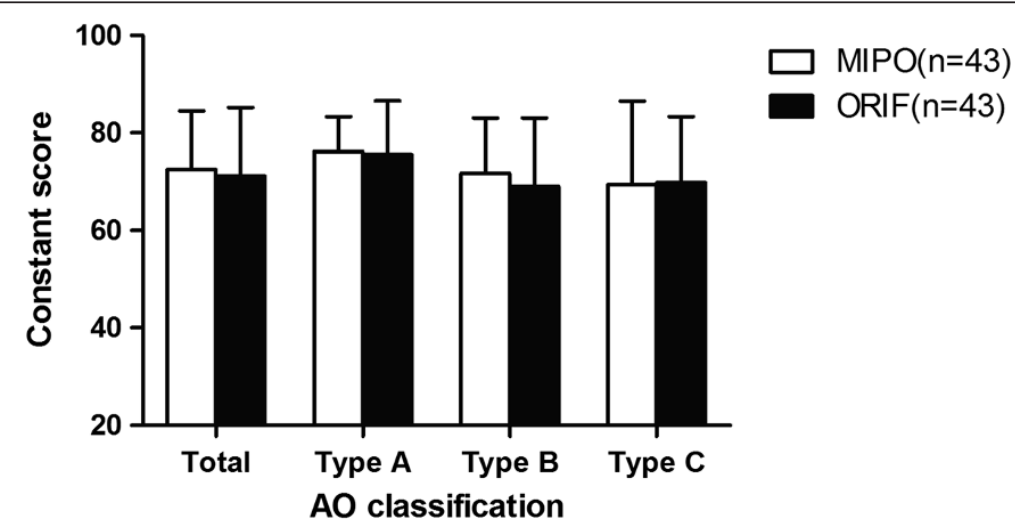

Figure 3 Average scores for the fracture types based on the AO/ASIF fracture classification after12months of follow-up. Type Afractures had the highest average Constant score in both groups, followed by type B and C fractures. There were no significant differences toward the type of fracture and each type between groups $(p=0.205)$. 
Table 4 Complications after one year of follow-up

\begin{tabular}{lll}
\hline Complications & MIPO $(\mathbf{n}=\mathbf{4 3})$ & ORIF $(\mathbf{n}=\mathbf{4 3})$ \\
\hline Complications rate & $5(11.6 \%)$ & $4(9.3 \%)$ \\
Reoperations (\%) & $2(4.6 \%)$ & $2(4.6 \%)$ \\
Varus displacement & 1 & \\
Second loss of reduction & 2 & 1 \\
Nerve lesions & 1 & 2 \\
Impingement rates & 1 & 1 \\
Screw perforation & & \\
\hline
\end{tabular}

overall incidence of $58 \%$ and $62 \%$. It should be noted that clinical exam is not reliable in detecting nerve injuries, and an electromyography investigation is recommended for an accurate diagnosis [36,37].

Moreover, this study revealed that the surgical approach did not influence the complication rate and/or radiological outcomes. The complication rate of the MIPO group was less than $12 \%$, which is comparable to previous reports $[21,23,30,31,38]$. In the literature, the main complications with LCP are implant-related, including impingement, intra-articular screw perforation and the proximal screw loosening [21,22,31,33,38].

In our study, the major complication was secondary loss of reduction following a varus collapse of the fracture. This also resulted in subacromial impingement due to a reduced acromio-humeral distance. In these three patients, there was loss of medial hinge integrity due to impaction and osteoporosis, causing the fractures to be unstable. Recent studies have demonstrated a direct association between medial support and subsequent reduction loss [30,38]. In the MIPO group in this study, wound healing occurred faster and there was minimal scaring following surgery. Thus, patients might have engaged in early full weight bearing activities and functional exercises, leading to delayed healing.

The second major complication was subacromial impingement, which occurred in one plate in the MIPO group and two plates in the ORIF group. The plates were removed after radiograph confirmation of the fracture union at about 5 months. At the last follow-up, the patients achieved optimal functional outcomes with good range of motion.

In our study, the most frequent type of fracture was type B in both groups. The mean Constant score of type B fractures was more than in type $A$ and type $C$ fractures. These findings are similar to the report by Röderer and Brorson et al. [32,39], although our overall complication rate was much lower.

There are some limitations in our study. First, our study was retrospective in design. However, our study provided long-term results and outcomes of patients undergoing MIPO compared to ORIF. Second, the study was conducted at a single center with different surgeons. The surgeons were experienced and had expertise in MIPO and ORIF. Third, patients treated with MIPO underwent surgery 1-3 years later than the patients who were treated with ORIF. All the other parameters were similar between the two groups.

\section{Conclusion}

This study shows that MIPO with LCP requires less surgery time, causes less blood loss, shortens hospital stay,results in less scarring, and is cosmetically more appealing and acceptable to female patients compared to ORIF with LCP. Further, MIPO with LCP provides good functional results and has less morbidity at one year follow-up. MIPO with LCP for proximal humerus fractures is a safe and favorable option compared to ORIF with LCP.

\section{Abbreviations \\ LCP: Locking compression plate; MIPO: Minimally invasive plate osteosynthesis; ORIF: Open reduction and internal fixation; ADL: Activities of daily living; ROM: Range of motion.}

\section{Competing interests}

The authors have declared that no competing interest exists.

\section{Authors' contributions}

All authors have made substantial contributions to design, acquisition of data, and analysis and interpretation of data. DF and SY conceived the study. $\mathrm{TL}, \mathrm{XM}$ and DF were responsible for the design and the statistical analysis. $\mathrm{TL}$ and BX were involved in drafting the manuscript or revising it critically for important intellectual content. All the authors read and approved the final manuscript. DF and SY have given final approval of the version to be published.

\section{Acknowledgments}

We thank Medjaden Biosciences Ltd. for proofreading the manuscript.

Received: 15 October 2013 Accepted: 12 June 2014

Published: 16 June 2014

\section{References}

1. Helmy N, Hintermann B: New trends in the treatment of proximal humerus fractures. Clin Orthop Relat Res 2006, 442:100-108.

2. Wijgman AJ, Roolker W, Patt TW, Raaymakers EL, Marti RK: Open reduction and internal fixation of three and four-part fractures of the proximal part of the humerus. J Bone Joint Surg Am 2002, 84:1919-1925.

3. Lill H, Hepp P, Rose T, König K, Josten C: The angle stable Locking-ProximalHumerus-Plate (LPHP) for proximal humeral fractures using a small anterior-lateral-deltoid-splitting-approach-technique and first results. Zentralbl Chir 2004, 129:43-48.

4. Lill $H$, Josten $C$ : Conservative or operative treatment of humeral head fractures in the elderly? Chirurg 2001, 72:1224-1234.

5. Plecko M, Kraus A: Internal fixation of proximal humerus fractures using the locking proximal humerus plate. Oper Orthop Traumatol 2005, 17:25-50.

6. Gradl G, Dietze A, Kääb M, Hopfenmüller W, Mittlmeier T: Is locking nailing of humeral head fractures superior to locking plate fixation? Clin Orthop Relat Res 2009, 467(11):2986-2993.

7. Matziolis D, Kaeaeb M, Zandi SS, Perka C, Greiner S: Surgical treatment of two-part fractures of the proximal humerus: comparison of fixed-angle plate osteosynthesis and Zifkonails. Injury 2010, 41(10):1041-1046.

8. Wachtl SW, Marti CB, Hoogewoud HM, Jakob RP, Gautier E: Treatment of proximal humerus fracture using multiple intramedullary flexible nails. Arch Orthop Trauma Surg 2000, 120(3-4):171-175.

9. Gardner MJ, Griffith MH, Lorich DG: Helical plating of the proximal humerus. Injury 2005, 36:1197-1200. 
10. Smith J, Berry G, Laflamme Y, Blain-Pare E, Reindl R, Harvey E: Percutaneous insertion of a proximal humeral locking plate: an anatomic study. Injury 2007, 38(2):206-211.

11. Hepp P, Theopold J, Voigt C, Engel T, Josten C, Lill H: The surgical approach for locking plate osteosynthesis of displaced proximal humeral fractures influences the functional outcome. J Shoulder Elbow Surg 2008, 17:21-28.

12. Gardner MJ, Boraiah S, Helfet DL, Lorich DG: The anterolateral acromial approach for fractures of the proximal humerus. J Orthop Trauma 2008, 22(2):132-137.

13. Gerber $C$, Werner $C M$, Vienne $P$ : Internal fixation of complex fractures of the proximal humerus. J Bone Joint Surg Br 2004, 86:848-855.

14. Gardner MJ, Griffith MH, Dines JS, Briggs SM, Weiland AJ, Lorich DG: The extended anterolateral acromial approach allows minimally invasive access to the proximal humerus. Clin Orthop Relat Res 2005, 434:123-129.

15. Gardner MJ, Voos JE, Wanich T, Helfet DL, Lorich DG: Vascular implications of minimally invasive plating of proximal humerus fractures. J Orthop Trauma 2006, 20(9):602-627.

16. Robinson CM, Khan L, Akhtar A, Whittaker R: The extended deltoid-splitting approach to the proximal humerus. J Orthop Trauma 2007, 21(9):657-662.

17. Saran N, Bergeron SG, Benoit B, Reindl R, Harvey EJ, Berry GK: Risk of axillary nerve injury during percutaneous proximal humerus locking plate insertion using an external aiming guide. Injury 2010, 41(10):1037-1040.

18. Khan LA, Robinson CM, Will E, Whittaker R: Assessment of axillary nerve function and functional outcome after fixation of complex proximal humeral fractures using the extended deltoid-splitting approach. Injury 2009, 40(2):181-185.

19. Rouleau DM, Laflamme GY, Berry GK, Harvey EJ, Delisle J, Girard J: Proximal humerus fractures treated by percutaneous locking plate internal fixation. Orthop Traumatol Surg Res 2009, 95(1):56-62.

20. Karataglis D, Stavridis SI, Petsatodis G, Papadopoulos P, Christodoulou A: New trends in fixation of proximal humeral fractures: a review. Injury 2011 42(4):330-338

21. Röderer G, Erhardt J, Graf M, Kinzl L, Gebhard F: Clinical results for minimally invasive locked plating of proximal humerusfractures. J Orthop Trauma 2010, 24(7):400-406.

22. Acklin YP, Sommer C: Plate fixation of proximal humerus fractures using the minimally invasive anterolateral delta split approach. $O$ Acklin per Orthop Traumatol 2012, 24(1):61-73.

23. Gavaskar AS, Muthukumar S, Chowdary N: Biological osteosynthesis of complex proximal humerus fractures: surgical technique and results from a prospective single center trial. Arch Orthop Trauma Surg 2010, 130(5):667-672.

24. Röderer G, Sperfeld AD, Hansen P, Krischak G, Gebhard F, Kassubek J: Electrophysiological assessment of the deltoid muscle after minimally invasive treatment of proximal humerus fractures - a clinical observation. Open Orthop J 2011, 5:223-228.

25. Tan SL, Balogh ZJ: Indications and limitations of locked plating. Injury 2009, 40(7):683-691.

26. Röderer G, Abouelsoud M, Gebhard F, Böckers TM, Kinzl L: Minimally invasive application of the non-contact-bridging (NCB) plate to the proximal humerus: an anatomical study. J Orthop Trauma 2007, 21(9):621-627.

27. Brunner A, Thormann S, Babst R: Minimally invasive percutaneous plating of proximal humeral shaft fractures with the Proximal Humerus Internal Locking System (PHILOS). J Shoulder Elbow Surg 2012, 21(8):1056-1063.

28. Ruchholtz S, Hauk C, Lewan U, Franz D, Kühne C, Zettl R: Minimally invasive polyaxial locking plate fixation of proximal humeral fractures: a prospective study. J Trauma 2011, 71(6):1737-4174.

29. Südkamp N, Bayer J, Hepp P, Voigt C, Oestern H, Kääb M, Luo C, Plecko M, Wendt K, Köstler W, Konrad G: Open reduction and internal fixation of proximal humeral fractures with use of the locking proximal humerus plate. Results of a prospective, multicenter, observational study. J Bone Joint Surg Am 2009, 91(6):1320-1328.

30. Zhang L, Zheng J, Wang W, Lin G, Huang Y, Zheng J, Edem Prince GA, Yang G: The clinical benefit of medial support screws in locking plating of proximal humerus fractures: a prospective randomized study. Int Orthop 2011, 35(11):1655-1661.

31. Geiger EV, Maier M, Kelm A, Wutzler S, Seebach C, Marzi I: Functional outcome and complications following PHILOS plate fixation in proximal humeral fractures. Acta Orthop Traumatol Turc 2010, 44(1):1-6.
32. Röderer G, Erhardt J, Kuster M, Vegt P, Bahrs C, Kinzl L, Gebhard F: Second generation locked plating of proximal humerus fractures-a prospective multicentre observational study. Int Orthop 2011, 35(3):425-432.

33. Erhardt JB, Roderer G, Grob K, Forster TN, Stoffel K, Kuster MS: Early results in the treatment of proximal humeral fractures with a polyaxial locking plate. Arch Orthop Trauma Surg 2009, 129(10):1367-1374.

34. Apaydin N, Tubbs RS, Loukas M, Duparc F: Review of the surgical anatomy of the axillary nerve and the anatomic basis of its iatrogenic and traumatic injury. Surg Radiol Anat 2010, 32(3):193-201.

35. Cheung S, Fitzpatrick M, Lee TQ: Effects of shoulder position on axillary nerve positions during the split lateral deltoid approach. J Shoulder Elbow Surg 2009, 18(5):748-755.

36. Visser CP, Coene LN, Brand R, Tavy DL: Nerve lesions in proximal humeral fractures. J Shoulder Elbow Surg 2001, 10(5):421-427.

37. Visser CP, Tavy DL, Coene LN, Brand R: Electromyographic findings in shoulder dislocations and fractures of the proximal humerus: comparison with clinical neurological examination. Clin Neurol Neurosurg 1999, 101(2):86-91

38. Osterhoff G, Ossendorf C, Wanner GA, Simmen HP, Werner CM: The calcar screw in angular stable plate fixation of proximal humeral fractures-a case study. J Orthop Surg Res 2011, 6:50.

39. Brorson S, Frich LH, Winther A, Hróbjartsson A: Locking plate osteosynthesis in displaced 4-part fractures of the proximal humerus. Acta Ortho 2011, 82(4):475-481.

doi:10.1186/1471-2474-15-206

Cite this article as: Lin et al:: Minimally invasive plate osteosynthesis with a locking compression plate is superior to open reduction and internal fixation in the management of the proximal humerus fractures. $B M C$ Musculoskeletal Disorders 2014 15:206

\section{Submit your next manuscript to BioMed Central and take full advantage of:}

- Convenient online submission

- Thorough peer review

- No space constraints or color figure charges

- Immediate publication on acceptance

- Inclusion in PubMed, CAS, Scopus and Google Scholar

- Research which is freely available for redistribution

Submit your manuscript at www.biomedcentral.com/submit
C Biomed Central 